\title{
Shape Modification is Common in Woven EndoBridge- Treated Intracranial Aneurysms: A Longitudinal Quantitative Analysis Study
}

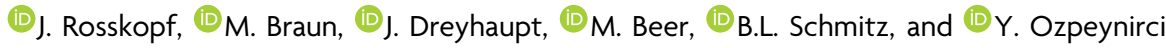

\begin{abstract}
BACKGROUND AND PURPOSE: After endovascular treatment of intracranial aneurysms with the Woven EndoBridge (WEB) device, worsening of aneurysm occlusion or re-opening was reported to be possibly associated with WEB shape modification. This study analyzed quantitatively the WEB shape modification with time in association with anatomic results.
\end{abstract}

MATERIALS AND METHODS: Thirty patients with 32 WEB-treated intracranial aneurysms fulfilled the inclusion criteria of cranial CT at baseline (day of intervention) and a follow-up CT at least $>1$ months' later (median follow-up time, 11.4 months; interquartile range, $6.5-21.5$ months). Adequate occlusion was observed in $84.4 \%$, and aneurysm remnant, in $15.6 \%$. WEB shape modification was quantified by a semiautomated approach on CT scans. Time courses were evaluated graphically and analytically; association analyses were performed by linear mixed-effects regression models.

RESULTS: In 29/32 WEB devices (90.6\%), the reduction in height was found to be at least $5 \%$. The decrease in height with time was significantly associated with the time interval in days since the intervention $(P<.0001)$ : A stronger decrease in WEB height was associated with a longer time since the intervention (median reduction in 1 year, 19.2\%; range, 8.6\%-52.3\%). No significant association was found with the quality of aneurysm occlusion, device size, rupture status of the aneurysm, aneurysm location, and reintervention rate.

CONCLUSIONS: Shape modification was common in WEB-treated intracranial aneurysms with a median height reduction of $19.2 \%$ in 1 year. The quality of aneurysm occlusion was not associated with WEB modification.

ABBREVIATIONS: ASA = acetylsalicylic acid; SL = single-layer; SLS = single-layer sphere; WEB = Woven EndoBridge

A s a novel endovascular aneurysm occlusion device, the Woven EndoBridge (WEB) (Sequent Medical) was designed to divert the intrasaccular flow, promoting intra-aneurysmal clot formation. ${ }^{1}$ Although the safety and efficacy of the WEB have been confirmed in several clinical trials, ${ }^{2-9}$ some uncertainty still remains about the WEB shape-modification phenomenon reported to be possibly associated with worsening of aneurysm occlusion during followup. ${ }^{10-12}$ The underlying mechanisms of WEB shape modification are rarely investigated, and corresponding theories range from clot

Received March 26, 2020; accepted after revision May 27.

From the Department of Radiology (J.R., M. Beer, B.L.S.), Institute of Epidemiology and Medical Biometry (J.D.), University of Ulm, Ulm, Germany; Department of Neuroradiology (M. Braun, B.L.S.), Bezirkskrankenhaus Günzburg, Günzburg, Germany; and Institute of Neuroradiology (Y.O.), Ludwig Maximilian University, Munich, Germany

Please address correspondence to Johannes Rosskopf, MD, Department of Radiology, University of Ulm, Albert-Einstein-Allee 23, 89081 Ulm, Germany; e-mail: johannes.rosskopf@uni-ulm.de

Indicates article with supplemental on-line photos.

http://dx.doi.org/10.3174/ajnr.A6669 retraction to high arterial inflow. ${ }^{13-16}$ Therefore, quantitative measurement of WEB shape modification might be valuable for association analysis of anatomic results across time. Of note, only 1 previous DSA-based study reported descriptive results from a quantitative WEB shape-modification assessment without performing association analysis. ${ }^{16}$

The present study aimed to quantify the reduction in height of the WEB device in mid- and long-term follow-up. On the basis of findings of DSA studies, ${ }^{16,17}$ we hypothesized that the decrease in height assessed on successive CT scans by the use of a semiautomated approach would be common in WEB-treated aneurysms and would correlate across time. Furthermore, no association of the quality of aneurysm occlusion with WEB shape modification was expected. Finally, association analyses were performed with anatomic and clinical parameters like device size, rupture status of the aneurysm, aneurysm location, and re-intervention rates.

\section{MATERIALS AND METHODS Study Population}

The study was approved by the ethics committee of the University of Ulm, Ulm, Germany (reference \#16/20), and the 
requirement for patient consent was waived because of its retrospective nature.

All patients who underwent endovascular treatment with a WEB device between April 2013 and April 2020 were collected from our institutional data base. Single-layer (SL) and single-layer sphere (SLS) WEB devices were used for treatment of the aneurysms. Inclusion criteria were cranial CT at baseline (the day of the intervention) and a follow-up CT at least $>1$ months' later. Aneurysms treated with additional devices like coils and stents were excluded.

In our institution, the decision-making process between surgery or endovascular treatment of aneurysms was performed on a case-by-case basis by a multidisciplinary team of neurologists, neurosurgeons, and interventional neuroradiologists.

\section{Treatment Technique}

Our institutional standard procedure has been previously described in detail. ${ }^{18}$ In brief, endovascular aneurysm treatment with the WEB was performed with the patient under general anesthesia on a biplane angiographic system (Axiom Artis zee; Siemens, Erlangen, Germany) by 4 interventional neuroradiologists. Unilateral femoral puncture was accompanied by a single intravenous heparin bolus of $5000 \mathrm{IU}$ without further systemic heparinization during or after the procedure. After navigating the guiding catheter into the relevant supraaortic artery, the aneurysm was catheterized with a dedicated VIA microcatheter (Sequent Medical). Aneurysm measurements were performed on $3 \mathrm{D}$ rotational angiography images and $2 \mathrm{D}$ working projections on 2 planes. According to the manufacturer's instructions, the WEB device was slightly oversized to exceed the average width of the aneurysm sac by at least $1 \mathrm{~mm}$ to secure the maximum stable position inside the aneurysm. A control angiogram, including a 3D rotational angiography in complex cases, verified the optimal opening and location of the WEB. A routine postoperative nonenhanced cranial CT (Brilliance 40; Philips Healthcare) was performed to exclude an immediate procedure-related complication. Scan parameters were as follows: 40-detector row multidetector CT, $80 \mathrm{kV}, 556 \mathrm{~mA}$, volume CT dose index $=23.5 \mathrm{mGy}, 0.75$-second gantry rotation time, pitch $=0.675$, section width $=$ $0.54 \mathrm{~mm}$.

\section{Antiplatelet Regimen}

Pre- and postoperative antiplatelet regimens were the following: Unruptured cases received $100 \mathrm{mg}$ of acetylsalicylic acid (ASA) and $75 \mathrm{mg}$ of clopidogrel 5 days before treatment if possible. Otherwise, they were loaded with $500 \mathrm{mg}$ of ASA and $375 \mathrm{mg}$ of clopidogrel the day before treatment. Depending on the extent of WEB protrusion into the parent vessel or neck size of the aneurysm, either a double-antiplatelet regimen for a further 46 weeks or a single-antiplatelet regimen ( $100 \mathrm{mg}$ of ASA daily) for up to 3 months was continued. In ruptured aneurysms, a single antiplatelet, usually ASA, $100 \mathrm{mg}$ daily, was given for 46 weeks.

In case of periprocedural thromboembolic complications irrespective of rupture status, intravenous tirofiban (Aggrastat) was administered during the procedure and usually continued for 4-
6 hours, followed by a loading dose of ASA (500 mg) and clopidogrel $(375 \mathrm{mg})$. Maintenance double-antiplatelet therapy was continued as described above.

\section{Follow-Up and Reevaluation of Images}

Follow-up angiographic controls with DSA or CTA were scheduled, depending on the preceding results. Imaging data were independently re-evaluated on the 3 -grade scale derived from the WEB Occlusion Scale ${ }^{19}$ by 3 interventional neuroradiologists (J.R., Y.O., and M. Braun) in a random order. In case of disagreement, consensus was found between 2 interpreters with the help of the most experienced senior neuroradiologist (B.L.S.). Adequate occlusion was defined as complete occlusion or neck remnant. ${ }^{20}$ Taken together, the quality of aneurysm occlusion was determined by the classification on the 3-grade scale as well as the differentiation between adequate and inadequate occlusion.

\section{Image Analysis}

The decrease in height of the WEB device was used as a surrogate for shape modification. On thin-section cranial CT scans with a section width of $0.54 \mathrm{~mm}$, reduction in height was quantified in a semiautomatic multistage process by the use of the software package ImageJ 1.52a (National Institutes of Health). ${ }^{21}$ The detailed step-by-step method is illustrated in On-line Fig 1. Briefly, this included the following: 1) image reconstruction of the WEB device, overturning the principal axis to the maximum distance between the proximal marker (near the aneurysm neck) and the distal marker (near the aneurysm apex), 2) bridging the distance between the 2 markers on the image by placing a line specifically chosen to be slightly less dense than the markers, and 3) determining the full width at half maximum between the 2 by linebridged markers of the WEB.

\section{Statistical Analysis and Time Course Analysis}

All statistical analyses were performed using SAS (version 9.4; https://www.sas.com/en_us/software/sas9.html) and R statistical and computing software (Version 3.5.1; http://www.rproject.org/). For statistical analysis, measured values for the height of the WEB device in millimeters were converted to percentage values in each case by defining baseline as $100 \%$ and the follow-up scan as the corresponding decrease in height in percentage from baseline. Linear mixed-effects regression models were used to examine the influence of time, aneurysm occlusion rate, device size, rupture status, aneurysm location, and reintervention rate on the quantified deepening of the proximal and distal concave recesses of the WEB device across time. A 2sided $P$ value of .05 was considered statistically significant. Due to the exploratory nature of this study, all results from statistical tests have to be interpreted as hypothesis-generating. An adjustment for multiple testing was not performed. The measurement error was determined on 11 randomly selected patients (10\% of the total number of measurements, $n=111$ ). WEB height varied between $-3.1 \%$ and $+3.4 \%$. Therefore, a decrease of $>5 \%$ was considered relevant.

Time course analysis of WEB shape modification was performed graphically and analytically. In each case of an 
investigated WEB-treated aneurysm, the decrease of WEB height across time in days was visualized as line graphs, yielding a total of 32 graphs. For analytic analysis, the slopes from a univariate linear regression model separate for each WEB device were calculated (individual changes in percentage/month). Derived from this, the median annual reduction was determined. All available data were used in each WEB device for this calculation.

Table 1: Follow-up aneurysm occlusion rates on a 3-grade scale

\begin{tabular}{lc}
\hline Anatomic Results at Follow-Up & Total (\%) \\
\hline Complete occlusion (grade 1) & $13 / 32(40.6)$ \\
Neck remnant (grade 2) & $8 / 32(25.0)$ \\
Aneurysm remnant (grade 3) & $11 / 32(34.4)$ \\
Retreatment & $5 / 32(15.6)$ \\
Complication rate & $2 / 32(6.3)$ \\
\hline
\end{tabular}

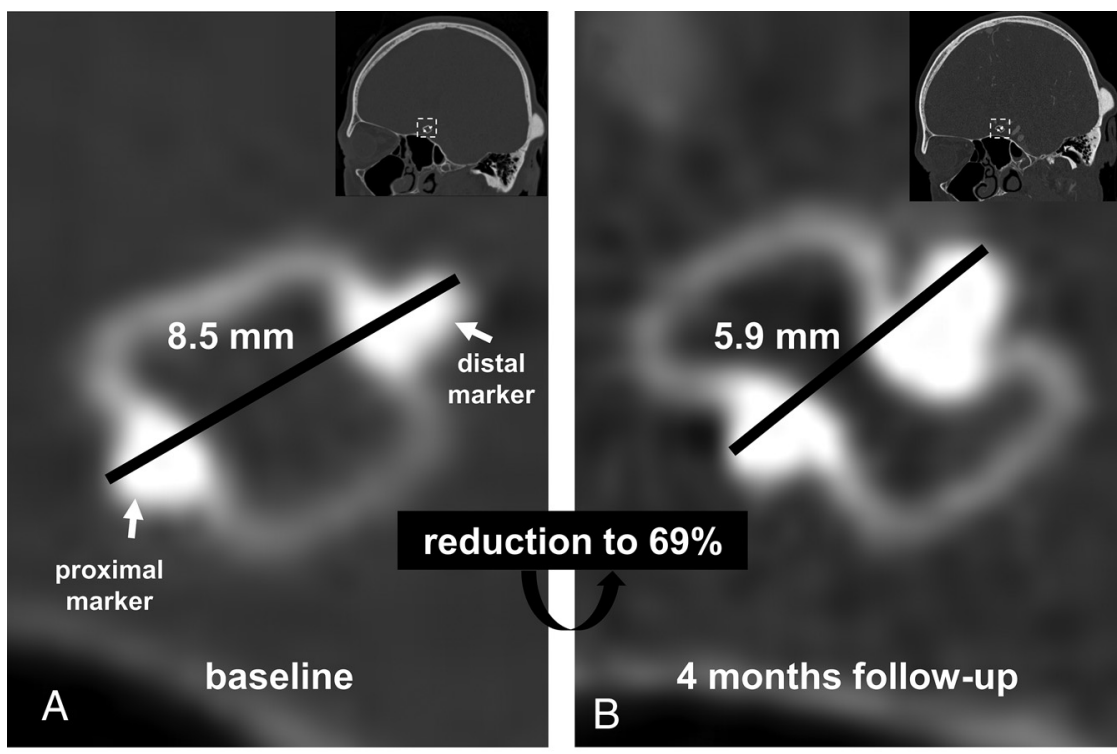

elliptical sphere

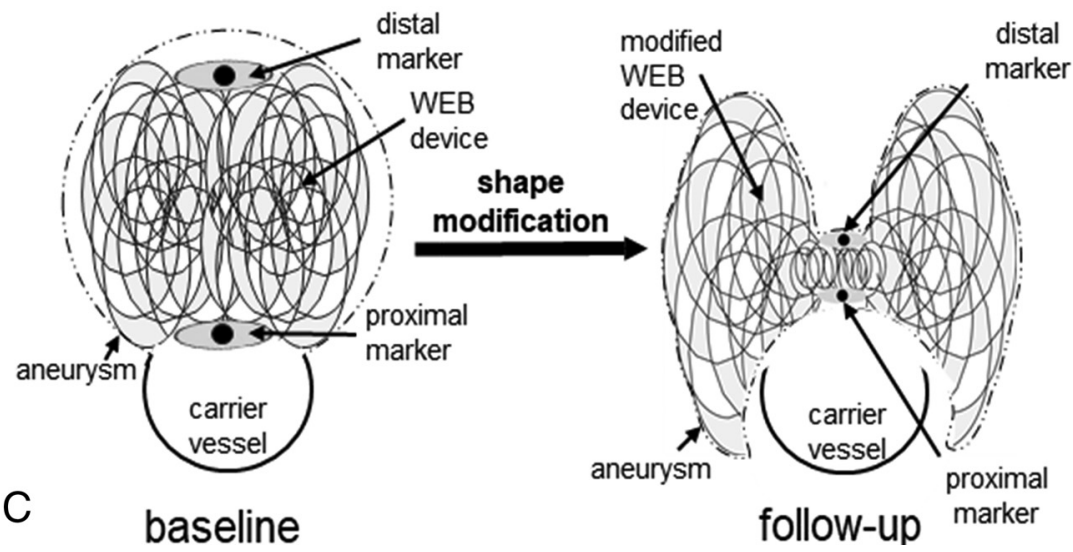

FIG 1. Aneurysm at the anterior communicating artery treated with a $7 \times 4$ WEB device (SL) on $C T$ at the day of the intervention (baseline) $(A)$ and 4 months later (B). The distance (black line) between the proximal marker (near the aneurysm neck) and the distal marker (near the aneurysm apex) decreases from 8.5 to $5.9 \mathrm{~mm}$, yielding a reduction to $69 \%$. Schematic illustration (C) of WEB shape modification from an elliptical sphere at baseline to a figure that might be comparable with a "butterfly shape" on follow-up. With deepening of the proximal and distal marked concave recesses, the WEB device appears to be shaped in the middle like the trunk of a butterfly and its wings are a semicircle that encompasses the carrier vessel due to elements of the WEB device being pushed aside.

\section{Study Population}

Sixty-seven patients with aneurysms were treated with the WEB device between April 2013 and April 2020 in our institution. Thirty patients with 32 WEB-treated aneurysms (2 patients with 2 aneurysms) fulfilled the inclusion criteria of baseline CT and follow-up CT at least $>1$ months' later. Thirty-seven patients treated with the WEB device were excluded because aneurysms were occluded with additional devices (coils and stents) or the patient's CT image timeline did not fulfill the inclusion criteria, respectively. The mean patient age of 6 men and 24 women was $56.5 \pm 10.4$ years (range, 39.0-79.0 years). Thirty WEB-SL devices (93.8\%) and 2 WEB-SLS devices (6.3\%) with a minimum of $3.5 \times 2 \mathrm{~mm}$ to a maximum of $11 \times 9 \mathrm{~mm}$ were used. Thirteen ruptured (40.6\%) and 19 unruptured (59.4\%) WEBtreated aneurysms were located at the intradural internal carotid artery or middle cerebral artery in $8 / 32$ (25.0\%), at the anterior communicating artery in 13/32 (40.6\%), and at the posterior inferior cerebellar artery or superior cerebellar artery or basilar artery in 11/32 (34.4\%). The median of the latest CT follow-up was 11.4 months, with an interquartile range of 6.5-21.5 months comprising 9/32 (28.1\%) cases with 1-time follow-up, $10 / 32(31.3 \%)$ cases with 2-time, 4/32 (12.5\%) cases with 3-time, 7/32 (21.9\%) cases with 4-time, and $2 / 32$ (6.3\%) cases with 5-time followup measurements. In 10/32 cases (31.3\%), long-term data with the follow-up time exceeding the 18-month interval were available.

\section{Anatomic Results and Complications}

Anatomic results were evaluated on CTA follow-up scans and DSA. Adequate occlusion was observed in $27 / 32$ (84.4\%), and aneurysm remnant, in 5/32 (15.6\%) cases. Results of the detailed 3-grade scale are summarized in Table 1. In 5 cases, reintervention due to inadequate occlusion was necessary, with additional coiling in 3 cases (within a delay of 4,5 , and 8 months, respectively) as well as stent placement in 2 cases (delay of 5 and 8 months, respectively). One thromboembolic event occurred, and another patient had a dissection of the internal carotid artery. In both situations, the patients remained asymptomatic. 
Table 2: Results of association analysis of WEB shape modification and anatomic results performed by mixed-effects regression models

\begin{tabular}{lcc}
\hline \multicolumn{1}{c}{ Parameters } & Regression Coefficient (95\% Confidence Interval) & $\boldsymbol{P}$ Value \\
\hline Time course (days) & $-0.00017(-0.00023$ to -0.00011$)$ & $<.001$ \\
Aneurysm occlusion rate & $0.02722(-0.05656-0.1110)$ & .52 \\
Device size (mm) & $0.002948(-0.01371-0.01961)$ & .73 \\
Rupture status of aneurysm (ruptured vs unruptured) & $-0.01868(-0.08609-0.04873)$ & .58 \\
Aneurysm location & $0.04867(-0.02391-0.1213)$ & .40 \\
& $0.01904(-0.06410-0.1022)$ & .10 \\
Reintervention (yes vs no) & $-0.07277(-0.1588-0.01329)$ & \\
\hline
\end{tabular}

${ }^{a}$ A 2-sided $P$ value of .05 is considered statistically significant.

\section{Association Analysis}

In 29/32 WEB devices (90.6\%), the reduction in height was found to be at least $5 \%$ (Fig 1). The decrease in height across time was significantly associated with the time interval in days since the intervention $(P<.0001)$; a stronger decrease in WEB height was associated with a longer time since the intervention, with an average $0.017 \%$ decrease (95\% confidence interval, $0.011 \%-0.023 \%$ ) per day. Adequately occluded aneurysms by the WEB had a $2.7 \%$ (95\% confidence interval, $-5.7 \%-11.1 \%$ ) greater decrease in the height of the WEB than the aneurysm remnant, which was not significant $(P=.52)$ and in line with results of the association analysis with the aneurysm occlusion rate on the detailed 3-grade scale $(P=.78)$. Rupture status of the aneurysm, aneurysm location, and re-intervention rate were not significantly related to the degree of shape modification $(P=.58, P=.40$, and $P=.10)$ (Table 2).

\section{Time Course Analysis of WEB Shape Modification}

The graphic analysis (On-line Fig 2) of the depicted line graphs of each WEB-treated aneurysm case separately revealed mixed patterns of shape modification, with a continuous strong as well as weak decrease in the WEB height during the time course. However, cases with an initial strong decrease and a subsequent plateau phase were also observed. The analytic analysis of the depicted line graphs via univariate linear regression model analysis separate for each WEB device revealed a median slope reduction in percentages per month of $-1.599 \%$ (interquartile range, -0.143 to $-0.024 \%$ ), yielding an annual median reduction of $19.2 \%$ (interquartile range, $8.6 \%-52.3 \%$ ).

\section{DISCUSSION}

In the current study, we quantitatively analyzed shape modification of the WEB device during follow-up of 32 WEB-treated aneurysms and evaluated its association with anatomic results. By means of a semiautomated approach on CT scans, shape modification was common in WEB-treated aneurysms (90.6\%). The decrease in height was statistically significant across time. No significant association was found between shape change and the quality of aneurysm occlusion, device size, rupture status of the aneurysm, aneurysm location, or re-intervention rate. The graphic and analytic evaluation of time courses revealed mixed patterns of shape modification, with a median slope reduction of $19.2 \%$ per year.

As a novelty aspect of the present study, the shortening of the distance between the proximal and distal markers of the WEB device as a surrogate for shape modification was assessed quantitatively on CT scans by a semiautomated method and revealed a higher rate of WEB modification of $90.6 \%$ compared with previously reported rates of $25 \%-73 \%,{ }^{10,11,13,14}$ most likely due to different study designs with solely qualitative methods.

WEB shape modification was not associated with the quality of aneurysm occlusion as already previously reported by Janot et al. ${ }^{16}$ The exact mechanism of shape modification of the WEB device is not clear yet. Cognard and Januel ${ }^{10}$ assessed this issue as a hemodynamic phenomenon and suggested a water-hammer effect due to high arterial inflow. Caroff et $\mathrm{al}^{13}$ were able to show a clear association with aneurysm flow exposure using computational fluid dynamics simulations in a series of 19 aneurysms. They detected shape change in $57.9 \%$ (11/19) of aneurysms. It might be deductive because of the tendency of higher aneurysmal inflow in bifurcation aneurysms for which the WEB device was initially used. However, they also reported 3 cases (3/11, 27.2\%) with low inflow, which also showed shape modification during follow-up. Additionally, Pierot ${ }^{15}$ interpreted WEB shape modification rather as a part of a healing process initiated with thrombus formation, continuing with clot retraction, and eventually ending with fibrosis or formation of scar tissue.

Results of the present study confirmed that shape modification might be a healing process because no association with worsening of occlusion was found. During this process, we found that the WEB device underwent a change of form from an elliptical sphere into a figure that might be comparable with a "butterfly shape" (Fig 1C); with shortening of the distance between 2 markers, the markers in the middle represented the trunk and the bilateral wires pushed aside represented the wings. Moreover, in the present series, device size, rupture status, and the re-intervention rate appeared to play a minor role in shape modification of the WEB because no significant association with a decrease in WEB height was observed. Most interesting, Caroff et $\mathrm{al}^{13}$ also found no statistically significant association of device modification with aneurysm volume, aspect ratio, or neck size in a cohort of 22 patients with WEB-treated unruptured middle cerebral artery or basilar tip aneurysms.

In the current study, time course evaluation revealed a mixed pattern of continuous decline in device height with different slopes. Janot et al ${ }^{16}$ previously investigated WEB shape modification quantitatively on DSA at the end of the procedure and on control angiograms at 6 and 18 months. They reported that most of the shape modifications were already noticed at short-term follow-up (6-month DSA) and increased across time until the 18month control. In our series, it was not possible to distinguish between distinct follow-up points in time due to extremely 
different CT follow-up timelines among the patients. However, our results indicated a statistically significant continuous decrease of WEB height also beyond the 18-month interval because our analysis included quantitative data up to a 5.9-year interval.

Limitations of the study included its retrospective design and the relatively small sample size. Furthermore, no subgroup analysis was performed between SL and SLS types of devices due to the unbalanced ratio (30 SLs versus 2 SLSs). Moreover, the artifacts produced by coils and stents did not allow determining the distance between the 2 WEB markers by the developed semiautomated approach. Thus, for methodologic reasons, aneurysms treated with additional devices had to be excluded.

\section{CONCLUSIONS}

Ninety-one percent of patients treated with a WEB showed shape modification of the device during follow-up with a median annual reduction rate of $19 \%$ in height. WEB shape modification was not associated with the quality of aneurysm occlusion.

\section{REFERENCES}

1. Asnafi S, Rouchaud A, Pierot L, et al. Efficacy and safety of the Woven EndoBridge (WEB) device for the treatment of intracranial aneurysms: a systematic review and meta-analysis. AJNR Am J Neuroradiol 2016;37:2287-92 CrossRef Medline

2. Arthur AS, Molyneux A, Coon AL, et al; WEB-IT Study investigators. The safety and effectiveness of the Woven EndoBridge (WEB) system for the treatment of wide-necked bifurcation aneurysms: final 12-month results of the pivotal WEB intrasaccular therapy (WEBIT) study. J Neurointerv Surg 2019;11:924-30 CrossRef Medline

3. Pierot L, Moret J, Turjman F, et al. WEB treatment of intracranial aneurysms: clinical and anatomic results in the French Observatory. AJNR Am J Neuroradiol 2016;37:655-59 CrossRef Medline

4. Pierot L, Gubucz I, Buhk JH, et al. Safety and efficacy of aneurysm treatment with the WEB: results of the WEBCAST 2 study. AJNR Am J Neuroradiol 2017;38:1151-55 CrossRef Medline

5. Pierot L, Moret J, Barreau X, et al. Safety and efficacy of aneurysm treatment with WEB in the cumulative population of three prospective, multicenter series. J Neurointerv Surg 2018;10:556-62 CrossRef Medline

6. Pierot L, Klisch J, Liebig T, et al. WEB-DL endovascular treatment of wide-neck bifurcation aneurysms: long-term results in a European series. AJNR Am J Neuroradiol 2015;36:2314-19 CrossRef Medline

7. Gawlitza M, Soize S, Januel AC, et al. Treatment of recurrent aneurysms using the Woven EndoBridge (WEB): anatomical and clinical results. J Neurointerv Surg 2018;10:629-33 CrossRef Medline
8. Mine B, Goutte A, Brisbois D, et al. Endovascular treatment of intracranial aneurysms with the Woven EndoBridge device: mid term and long term results. J Neurointerv Surg 2018;10:127-32 CrossRef Medline

9. Van Rooij S, Peluso JP, Sluzewski M, et al. The new low-profile WEB 17 system for treatment of intracranial aneurysms: first clinical experiences. AJNR Am J Neuroradiol 2018;39:859-63 CrossRef Medline

10. Cognard C, Januel AC. Remnants and recurrences after the use of the WEB intrasaccular device in large-neck bifurcation aneurysms. Neurosurgery 2015;76:522-30 CrossRef Medline

11. Sivan-Hoffmann R, Gory B, Riva R, et al. One-year angiographic follow-up after WEB-SL endovascular treatment of wide-neck bifurcation intracranial aneurysms. AJNR Am J Neuroradiol 2015;36:232024 CrossRef Medline

12. Armoiry X, Turjman F, Hartmann DJ, et al. Endovascular treatment of intracranial aneurysms with the WEB device: a systematic review of clinical outcomes. AJNR Am J Neuroradiol 2016;37:868-72 CrossRef Medline

13. Caroff J, Mihalea C, Da Ros V, et al. A computational fluid dynamics (CFD) study of WEB-treated aneurysms: can CFD predict WEB "compression" during follow-up? J Neuroradiol 2017;44:262-68 CrossRef Medline

14. Herbreteau D, Bibi R, Narata AP, et al. Are anatomic results influenced by WEB shape modification? Analysis in a prospective, single-center series of 39 patients with aneurysms treated with the WEB. AJNR Am J Neuroradiol 2016;37:2280-86 CrossRef Medline

15. Pierot L. Letter: WEB aneurysm treatment-occlusion stability and “compression." Neurosurgery 2015;77:E666-67 CrossRef Medline

16. Janot K, Herbreteau D, Amelot A, et al. Quantitative evaluation of WEB shape modification: a five-year follow-up study. J Neuroradiol 2020;47:193-96 CrossRef Medline

17. Cagnazzo F, Ahmed R, Zannoni R, et al. Predicting factors of angiographic aneurysm occlusion after treatment with the Woven EndoBridge device: a single-center experience with midterm follow-up. AJNR Am J Neuroradiol 2019;40:1773-78 CrossRef Medline

18. Ozpeynirci Y, Braun M, Pala A, et al. WEB-only treatment of ruptured and unruptured intracranial aneurysms: a retrospective analysis of 47 aneurysms. Acta Neurochir (Wien) 2019;161:1507-13 CrossRef Medline

19. Fiorella D, Arthur A, Byrne J, et al. Interobserver variability in the assessment of aneurysm occlusion with the WEB aneurysm embolization system. J Neurointerv Surg 2015;7:591-95 CrossRef Medline

20. Rouchaud A, Brinjikji W, Ding YH, et al. Evaluation of the angiographic grading scale in aneurysms treated with the WEB device in 80 rabbits: correlation with histologic evaluation. AJNR Am J Neuroradiol 2016;37:324-29 CrossRef Medline

21. Schneider CA, Rasband WS, Eliceiri KW. NIH Image to ImageJ: 25 years of image analysis. Nat Methods 2012;9:671-75 CrossRef Medline 